\title{
HISTOLOGICAL AND IMMUNOHISTOCHEMICAL STUDY ON THE EFFECT OF MELATONIN IN RAT CEREBELLAR CORTEX INJURY AFTER TRANSIENT BILATERAL COMMON CAROTID ARTERY LIGATION
}

\author{
Gyy \\ Dalia A. Shabaan, Awny H. Yaseen, Amany S. EL-Lakany \\ and Amany A. El-Hawwary
}

Trom

Histology and Cell Biology Department, Faculty of Medicine,

Mansoura University, Egypt

\begin{abstract}
Brain ischemia is a condition in which there is insufficient blood flow to meet its metabolic demands leading to many functional and structural changes. The cerebellum is considered one of the vulnerable regions for brain ischemia. Melatonin, produced by the pineal gland, has antioxidant, anti-inflammatory and antiapoptotic effects. Therefore, the current study has been performed to evaluate the effect of melatonin administration on induced ischemic reperfusion injury $(\mathrm{I} / \mathrm{R})$ in rat cerebellar cortex. Thirty adult male albino rats were used and divided into three groups (10 rats / group). Group A contained the sham-control rats,
\end{abstract}

while group $B$ included I/R rats which were subjected to transient ischemia by ligation of both common carotid arteries simultaneously for $10 \mathrm{~min}$ utes and subdivided into 2 subgroups; B1 (3 days after I/R) and B2 (one month after $\mathrm{I} / \mathrm{R}$ ). Group $\mathrm{C}$ included I/R rats (as in group B) with intraperitoneal melatonin administration (in a dose of $5 \mathrm{mg} / \mathrm{kg}$ ) $30 \mathrm{~min}$ utes before performing ischemia and one \& three hours after release of ligation respectively and also was subdivided into 2 subgroups; C1 (3 days after I/R with melatonin administration) and C2 (one month after I/ $R$ with melatonin administration). The cerebellum was dissected and prepared to be stained with haema-

MANSOURA MEDICAL JOURNAL 
toxylen and eosin (H\&E). Also, immunohistochemical study was performed for detection of glial fibrillary acidic protein (GFAP) and p53 positive cells. Subgroup B1 sections showed shrunken Purkinje cells and apoptotic granular ones which were markedly increased in number in subgroup B2. These histological alterations were ameliorated in subgroup $\mathrm{C} 1$ sections with melatonin administration. The histological architecture of cerebellar cortex of subgroup C2 appeared more or less similar to the control group. Few p53 and GFAP positive cells in rat cerebellar cortex of subgroup B1 were observed with significant increase in subgroup B2. However, sections of subgroups $\mathrm{C} 1$ and $\mathrm{C} 2$ showed an apparent decrease in the number of positive cells of both immunohistochemical markers as compared to the corresponding $B$ subgroups.

It could be concluded that injection of melatonin could ameliorate $\mathrm{I} / \mathrm{R}$ associated changes in rat cerebellar cortex through a possible neuroprotective role.

Keywords: Melatonin, I/R, Cerebellar cortex, Apoptosis, Astrocytes

\section{INTRODUCSTION}

Ischemia refers to a condition produced by decreased perfusion whereby tissue receives less than the necessary amount of blood, oxygen, glucose, and other essential nutrients (1). The brain, including cerebellum, is one of the vulnerable regions subjected to damage due to ischemia. The severity of brain damage during ischemia is dependent on the thoroughness and duration of the interruption of neural blood flow. Alterations in flow thresholds cause different degrees of physiological disruption and tissue destruction (2). Ischemia may be a result of arterial embolism, vascular disease or anomalies of the coagulation process $(3,4)$. Furthermore, heart function and body temperature are critical determinants of the severity of neuronal damage and functional recovery following cerebral ischemia $(5,6)$.

Two types of ischemia can be induced in animals; global and focal. Global ischemia affects widespread brain areas but typically gives rise to neuronal alterations within selectively vulnerable brain regions. The cerebellum is regularly affected in global cerebral ischemia, and can be

Vol. 43, No. 1 \& 2 Jan. \& April, 2014 
devastated (7). By contrast, models of focal ischemia, either with or without reperfusion, leads to histopathology characterized by focal necrosis or infarction to a specific area of the brain (1).

Cellular damage after reperfusion of previously viable ischemic tissues is defined as ischemia-reperfusion (I/R) injury (8). Brain I/R injury leads to a complex series of pathophysiological events leading to neuronal death and subsequent neurological dysfunction (9). It involves oxidative stress damage $(10,11)$, inflammatory pathways (12), ionic imbalances, and apoptosis $(13,14)$. Ischemia initiates a complex process in which inflammation contributes to brain injury. The inflammatory response to neural tissue injury, including neutrophilia, lymphocytopenia and monocytosis, has been shown to be initiated as early as one hour after onset of ischemia and persists up to three months $(15,16,17)$.

Individual ischemic neurons may die from a mixed form of concurrent apoptosis and necrosis named hybrid death (18). Apoptosis and necrosis are probably triggered in parallel, and furthermore, the apoptotic path- way has been suggested to lead to necrosis (19). The morphological criteria for necrosis and apoptosis are well defined. Apoptosis refers to a process that involves an inherent cellular program leading to cell death (20). Necrosis is accidental cell death that results entirely from circumstances outside the cell and is manifested by karyolysis and cell swelling. Ischemic cell death is also characterized by a long delay between the insult and manifestation of major cell damage. This delay varies greatly, depending on the nature of the insult and the brain region being affected. In some cases it is as long as several days or even weeks, whereas in others it is a few hours or less (19). Reperfusion is the restoration of blood flow to the ischemic tissue. Despite its benefits to an ischemic tissue, reperfusion can elicit a cascade of adverse reactions that paradoxically injure tissues (21).

p53 induces apoptosis by controlling the translation of proapoptotic genes such as Bax, Puma and Noxa which trigger mitochondrial pathways, including cytochrome-C release and Caspase -3 accumulation. In addition, it also controls the downregulation of antiapoptotic gene such

MANSOURA MEDICAL JOURNAL 
42 HISTOLOGICAL AND IMMUNOHISTOCHEMICAL etc...

as $\mathrm{Bcl} 2$ (22,23). In the nucleus, p53 is a crucial transcriptional regulator and controls the program of transcription-dependent apoptosis in response to various signals, including DNA damage, oxidative stress, and ischemia (24).

Brain injury triggers an extensive glial cell response and activation (25). The glial response, collectively referred to as reactive gliosis, involves mainly activated astrocytes and microglia. Reactive gliosis is characterized by hypertrophic and proliferating astrocytes, and proliferating microglia (26). Reactive astrocytes are commonly observed in basically all pathologies in the central nervous system. They are characterized by cellular hypertrophy, an increase in number and upregulation of intermediate filament components, in particular GFAP and vimentin $(27,28)$. GFAP is the major component of intermediate filaments of mature astrocytes. Because of its specificity and abundance, expression of GFAP has become the most common marker used for astrocytes to recognize the astrocyte population in response to brain injury (29).

Melatonin ( $\mathrm{N}$-acetyl- 5-methoxytr- yptamine) is the chief indolamine produced by the pineal gland (30). It is a naturally occurring compound found in animals, plants and microbes (31). Melatonin has a molecular weight of 232 and is both lipid (32) and water soluble, although its solubility in lipid is clearly greater (33). It has two important functional groups which determine its specificity: the 5-methoxy group and the $\mathrm{N}$ acetyl side chain. Once synthesized, the majority of melatonin diffuses directly towards the cerebrospinal fluid of the brain third ventricle, while the other fraction is released into the blood stream where it is distributed to all tissues within a very short period $(34,35)$.

Melatonin has two major properties, antioxidant and antiinflammatory, which make it a viable candidate for treating various pathologies, including neurodegeneration as Alzhiemer's disease and Parkinson's disease (36). Melatonin is a potent free radical scavenger as well as an indirect antioxidant. It has been shown to be protective in gastrointestinal, myocardial and cerebral models of $\mathrm{I} / \mathrm{R}$ injury when it is given before ischemia and/or repeated doses started before reperfusion 
Dalia A. Shabaan et al...

(37). Moreover, Melatonin has several mechanisms in conferring neuroprotection after I/R by activation of its receptors in the cerebral blood vessels leading to vasodilation and normalising the perfusion of the ischemic region, preventing neurons from excitotoxic damage $(38,39)$ and prevention of subsequent apoptosis in neurons (40).

Therefore, the current study was designed to investigate the histological and immunohistochemical changes of $I / R$ in rat cerebellar cortex and to evaluate the possible protective effect of melatonin.

\section{MATERIALS AND METHODS}

Animals and Experimental design:

30 adult male rats weighing about 150 - $200 \mathrm{gm}$ were used in the present work. The animals were kept in adequate ventilation and temperature with regular $12 \mathrm{~h}$ light/dark cycle. All animals were given free access to standard laboratory food and water. The animals were equally divided into 3 groups (10 rats each). Group A was the sham-control rats that were subjected to a midline cervical incision with exposure of both common carotid arteries followed by closure of the incision. Group B included rats subjected to brain (I/R) to induce transient global brain ischemia. Both common carotid arteries were clamped simultaneously for only 10 minutes using "Bull dog" clamps through a midline neck incision followed by release of ligation and closure of the incision. This procedure was previously described by some researchers $(41,42,43,44)$. This group was further subdivided into subgroup B1 (3 days after $\mathrm{l} / \mathrm{R}$ ) and subgroup B2 (1 month after l/R). Group C included rats subjected to I/ $R$ injury (as group B) and intraperitoneal melatonin administration (Sigma- Aldrich Company) in a dose of 5 $\mathrm{mg} / \mathrm{kg}$, dissolved in absolute ethanol and diluted in isotonic saline to a final concentration of $1: 10$ then administered half an one hour prior to ischemia, one and two hours after reperfusion (45). Group C was further subdivided into subgroup $\mathrm{C} 1$ (3 days after $\mathrm{I} / \mathrm{R}$ ) and subgroup $\mathrm{C} 2$ (one month after $\mathrm{I} / \mathrm{R}$ ).

Histological and Immunohistochemistry Study:

The cerebellum was dissected and fixed in $10 \%$ neutral buffered formalin and processed to obtain 
44 HISTOLOGICAL AND IMMUNOHISTOCHEMICAL etc...

paraffin sections of $5 \mu$ thickness for light microscopic study. Sections were stained with H\&E stain (46). In addition, Paraffin sections of 4-5 um thick were prepared for immunohistochemical staining for p53 and GFAP for detection of apoptotic cells and astrocytes respectively (47). In addition, a specimen of human ovary with high grade serous papillary adenocarcinoma was obtained from the pathology department of Mansoura Faculty of Medicine and was prepared for p53 immunostaining as a positive control section.

Morphometric and Statistical Analysis:

Slides were photographed using Olympus ${ }^{\circledR}$ digital camera installed on Olympus ${ }^{\circledR}$ microscope using $40 \mathrm{X}$ objective. The result images were analyzed on Intel $\AA$ Core $13 \AA$ based computer using Video Test Morphology ${ }^{\circledR}$ software (Russia) with a specific built-in automated object counting routine for both $p 53$ and GFAP positive cells. Data were then tabulated, coded and analyzed using the computer program SPSS (Statistical package for social science) version 17.0 to obtain:

Vol. 43, No. 1 \& 2 Jan. \& April, 2014

\section{- Descriptive data:}

Descriptive statistics were calculated in the form of mean and standard deviation $( \pm S D)$.

\section{- Analytical statistics:}

In the statistical comparison between the different groups, the significance of difference was tested using ANOVA (analysis of variance) to compare between more than two groups of numerical (parametric) data followed by post-hoc tukey test for multiple comparisons.

A P value $<0.05$ was considered statistically significant and $P$ value $<0.001$ was considered highly significant in all analyses.

\section{RESULTS}

1) Haematoxylen and Eosinstained paraffin sections (H\&E):

Light microscopic examination of H\&E stained sections of the rat cerebellum of the control group showed its characteristic folia. It was composed of an outer cortex and an inner white matter. The cerebellar cortex was formed of outer molecular, middle Purkinje and inner granular layers (Fig.1). The molecular layer showed a sparse population of neurons including; basket cells near the 
Dalia A. Shabaan et al...

Purkinje cell layer and stellate cells near the surface. Also, it contained dendritic arborizations, nonmyelinated axons and radial fibers of neuroglial cells. Purkinje layer was formed of a single layer of large flask shaped cells with rounded euchromatic nuclei and a characteristic apical dendritic tree. They were surrounded by perineuronal neuroglia cells. The granular layer showed a large number of small cells with deeply stained nuclei of the granular cells, vesicular nuclei of Golgi cells and acidophilic non cellular areas in between the cells formed of synaptic complex of axons and dendrites, representing the cerebellar islands (Fig. 2).

In the cerebellar cortex of subgroup B1 (three days after I/R), empty spaces appeared around deformed and shrunken Purkinje cells which had condensed nuclei. Moreover, some apoptotic granular cells with small dark eccentric nuclei and an acidophilic cytoplasm were observed (Fig.3). Many distorted Purkinje cells surrounded by empty spaces as well as numerous apoptotic granular and neuroglial cells were encountered in subgroup B2 (one month after I/R) (Fig.4). However, in subgroup $\mathrm{C} 1$ (three days after I/R and melatonin treatment), the majority of Purkinje and granular cells appeared normal, while few apoptotic ones were seen in the granular layer (Fig.5). The histological architecture of cerebellar cortex in subgroup $\mathrm{C} 2$ (one month after $\mathrm{I} / \mathrm{R}$ and melatonin treatment), appeared more or less similar to the control group except for few apoptotic cells in the granular layer (Fig.6).

2) Immunohistochemical staining for $p 53$ :

Negative immunohistochemical staining for p53 was observed in sections of rat cerebellar cortex of control group A (Fig.7). In subgroup $B 1$, there were few p53 positive cells in the granular layer of rat cerebellar cortex (Fig.8), while in subgroup B2; there was also an apparent marked increase in p53 positive cells (Fig.9). In Subgroup C1, there was an apparent decrease in the number of positive cells in the granular layer of rat cerebellar cortex (Fig.10). The number of positive cells declined markedly in cererbellar cortex in subgroup C2 as compared to subgroup B2 (Fig. 11).

MANSOURA MEDICAL JOURNAL 


\section{HISTOLOGICAL AND IMMUNOHISTOCHEMICAL etc...}

3) Immunohistochemical stain- among different groups of the experiing for Glial Fibrillary Acidic Protein ment for both p53 and GFAP; among (GFAP):

Few positively stained cells were seen in the control cerebellar cortex after immunohistochemical staining for GFAP. This reaction was compared with control positive one in the white matter of cerebellum (Fig. 12). Subgroup B1, showed relative increase in GFAP- positive cells (Fig.13), whereas in subgroup B2, there was an apparent marked increase in positive cells in the granular layer of the cerebellar cortex (Fig.14). In the cerebellar cortex of subgroup $\mathrm{C} 1$, relatively few positive cells were observed (Fig. 15), while in subgroup $\mathrm{C} 2$, there was an apparent decrease in positive cells as compared to subgroup B2 (Fig.16).

4) Morphometric and statistical results:

The mean value, standard deviation and probability of both p53 and GFAP positive cells for all groups were shown in tables (1). ANOVA test revealed significant changes (control group A, subgroup B1 and subgroup $\mathrm{C} 1$ ) and also among (control group A, subgroup B2 and subgroup C2). Post-hoc tukey test showed the following:

The number of p53 and GFAP positive cells showed a statistically significant increase in $\mathrm{B} 1$ and $\mathrm{C} 1$ subgroups as compared to the control. In addition, the number of p53 positive cells in subgroup $\mathrm{C} 1$ was still significantly higher than the control group, while GFAP positive cells showed a non significant increase in C1. Similar results were obtained when comparing B2 with the control group and C2 subgroup in both p53 and GFAP. On the other hand, there was a significant increase in the number of p53 and GFAP positive cells in B2 as compared to B1 subgroups. The number of $\mathrm{p} 53$ positive cells was significantly higher in $\mathrm{C} 2$ than $\mathrm{C} 1$ subgroups, while GFAP positive cells showed a statistically non significant increase. 
Dalia A. Shabaan et al...

Table (1): p53 and GFAP positive cells in control and experimental groups:

\begin{tabular}{|c|c|c|c|c|c|c|}
\hline & & \multirow[b]{2}{*}{ Control -ve } & \multicolumn{2}{|c|}{ B } & \multicolumn{2}{|c|}{$\mathrm{C}$} \\
\hline & & & B1 & B2 & $\mathrm{C} 1$ & $\mathrm{C} 2$ \\
\hline \multirow{2}{*}{$\operatorname{Mean} \pm \mathbf{S D}$} & P53 & .00 & $15.67 \pm 2.73^{*}$ & $42.77 \pm 4.41^{* \diamond}$ & $6.53 \pm 2.00 \bullet \bullet \ddagger$ & $15.74 \pm 3.86$ \\
\hline & GFAP & $9.57 \pm 1.71$ & $16.73 \pm 3.70^{*}$ & $31.50 \pm 4.72^{* \diamond}$ & $10.95 \pm 1.79^{\bullet}$ & $12.2 \pm 2.59+$ \\
\hline
\end{tabular}

SD: standard deviation

Test used: ANOVA followed by post-hoc tukey

* : significance between Control-ve \& B groups

$\checkmark$ : significance between B \& C groups ?

- : significance between Control-ve \& $\mathrm{C}$ groups

b: significance between B1 \& B2 subgroups

O: significance between $\mathrm{C} 1 \& \mathrm{C} 2$ subgroups

$\ddagger$ : significance between $\mathrm{B} 1$ \& $\mathrm{C} 1$ subgroups

$\dagger$ : significance between B2 \& C2 subgroups

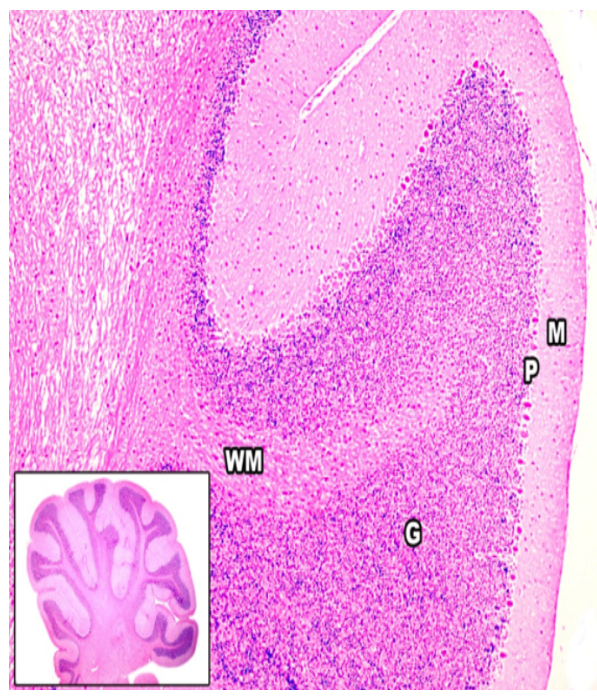

Fig 1: A photomicrograph of a paraffin section in a control rat cerebellar cortex demonstrating a part of cerebellar folium formed of an inner white mater (WM) covered by an outer cortex formed of molecular (M), Purkinje cell (P) and inner granular layer (G). The insert is the lower magnification of the cerebellar folia. (H\&E x 100, insert x 40)

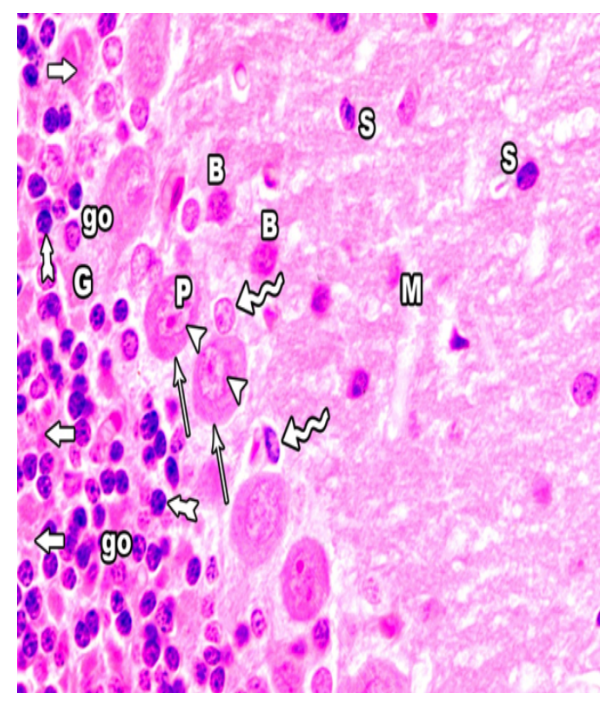

Fig 2: A photomicrograph of a paraffin section in the control rat cerebellar cortex showing molecular layer $(\mathrm{M})$, Purkinje layer $(\mathrm{P})$ and granular layer (G). The molecular layer shows nuclei of stellate cells (S) and of basket cells (B). The Purkinje layer is formed of large flask shaped cells (arrows) with rounded euchromatic nuclei (arrow heads). Perineuronal neuroglia cells (wavy arrows) are seen around Purkinje cells. The granular layer contains numerous small granular cells (tailed arrows) with darkly stained nuclei; Golgi cells (go) with vesicular nuclei and cerebellar islands (thick arrows) in between

MANSOURA MEDICAL JOURNAL 


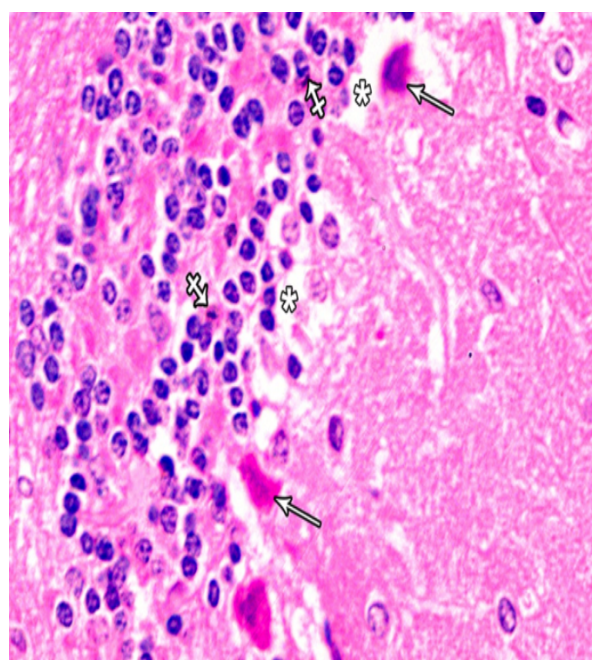

Fig 3: A photomicrograph of a paraffin section in rat cerebellar cortex three days after I/R Shrunken and deformed Purkinje cells surrounded by empty spaces (asterisks) having condensed nuclei (arrows) are seen. The granular layer shows many apoptotic cells with small eccentric nuclei and an acidophilic cytoplasm (crossed arrows). H\&E x 1000)

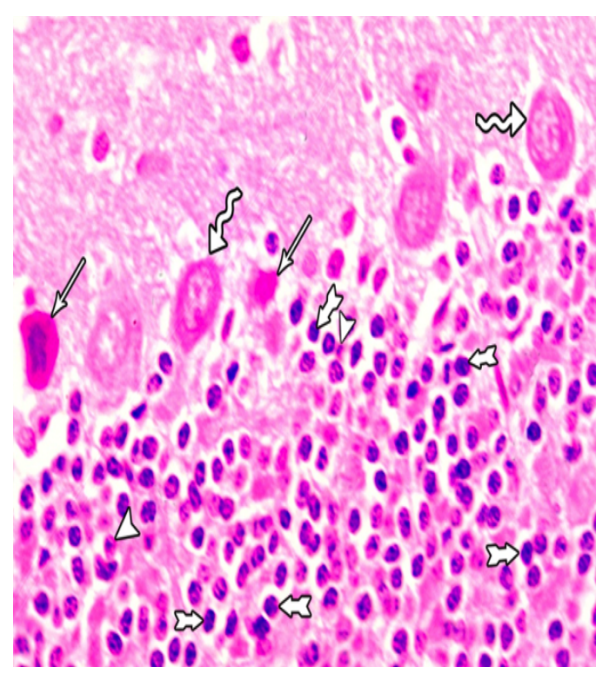

Fig 5: A photomicrograph of a paraffin section in cerebellar cortex of melatonin treated rat three days after I/R. Some Purkinje cells appear shrunken (arrows), while others are normal (wavy arrows). The majority of granular cells appear normal (tailed arrows), while few ones are apoptotic (arrow heads). (H\&E $\mathrm{X} 1000$ )

Vol. 43, No. 1 \& 2 Jan. \& April, 2014

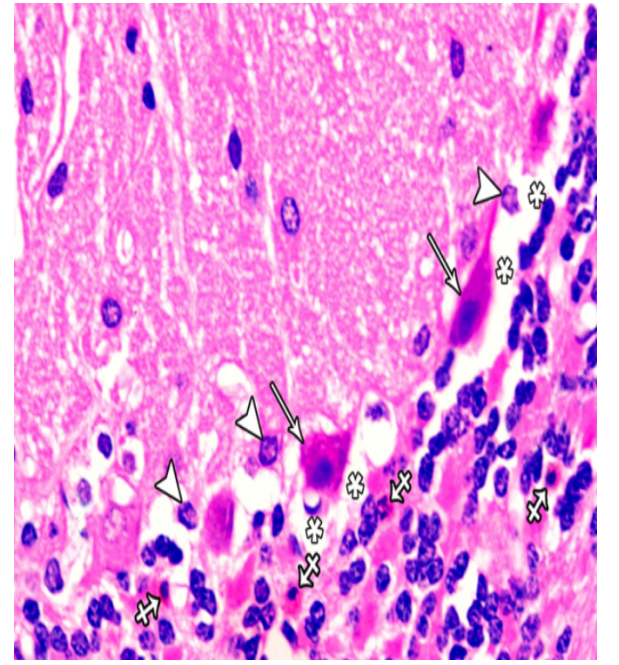

Fig 4: A photomicrograph of a paraffin section in a rat cerebellar cortex, one month after I/R, showing many distorted Purkinje cells with little acidophilic cytoplasm and dark nuclei (arrows). These cells are surrounded by empty spaces (asterisks) and numerous neuroglial cells (arrow heads). In the granular layer, many apoptotic cells (crossed arrows) are also seen. (H\&E x 1000)

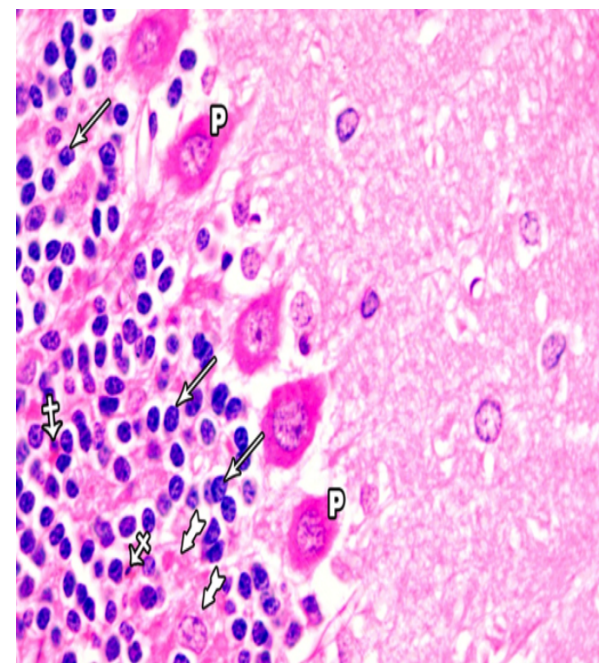

Fig 6: A photomicrograph of a paraffin section in cerebellar cortex of melatonin treated rat one month after I/R. Normal Purkinje cells (p), granular cells (arrows) and cerebellar islands (tailed arrows) are seen, while few apoptotic cells (crossed arrows) are also demonstrated. (H\&E x 1000) 
Dalia A. Shabaan et al...

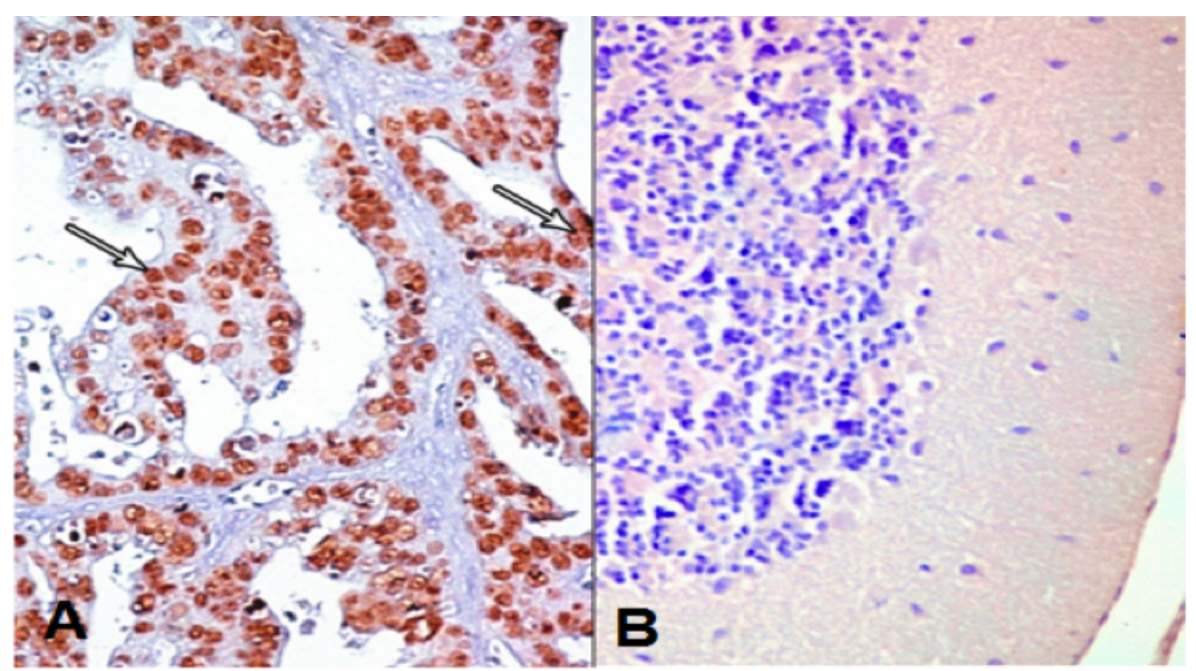

Fig 7: Photomicrographs of p53 control sections. A positive control section in human ovary with high grade serous papillary adenocarcinoma (A) showing numerous p53 positive cells with brownish coloration of the nuclei (arrows). Control rat cerebellar cortex (B) shows negative p53 reaction. (Anti p53 immunostaining A x1000, B x 400)

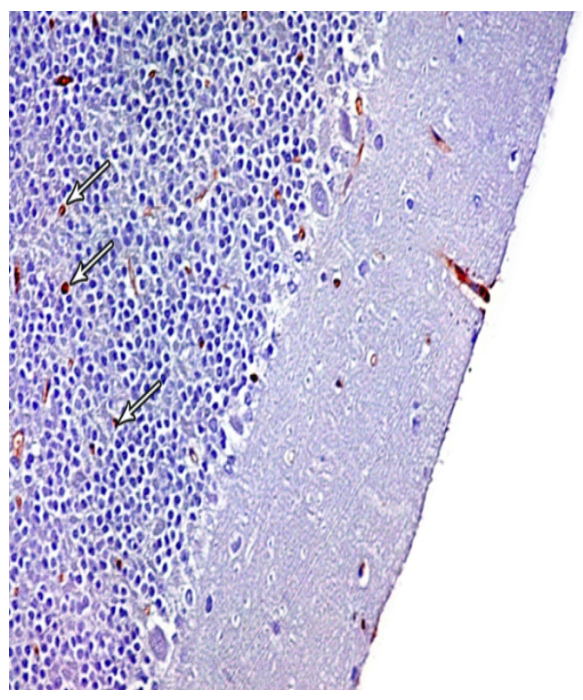

Fig 8: A photomicrograph of a section in a rat cerebellar cortex, three days after I/R, demonstrating few p53 positive cells mostly of the granular layer (arrows). (Anti p53 immunostaining $\mathrm{x}$ 400)

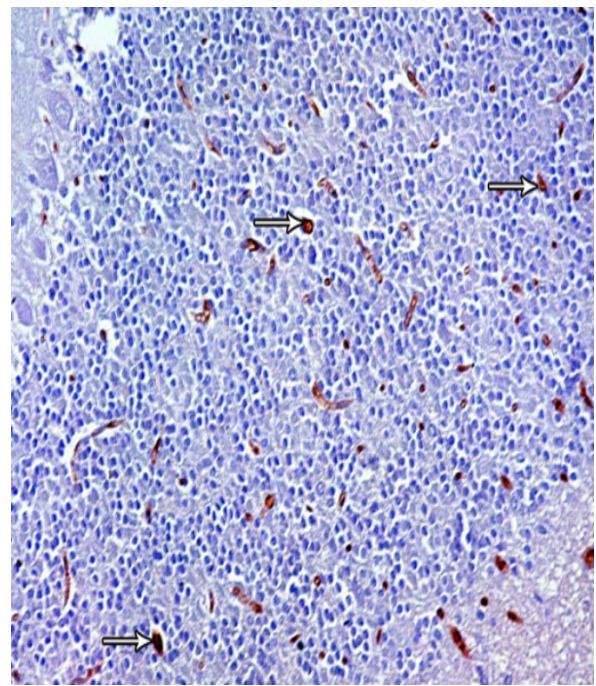

Fig 9: A photomicrograph of a section in a rat cerebellar cortex, one month after $\mathrm{I} / \mathrm{R}$, demonstrating numerous p53 positive cells. (Anti p53 immunostaining $\mathrm{x}$ 400)

MANSOURA MEDICAL JOURNAL 


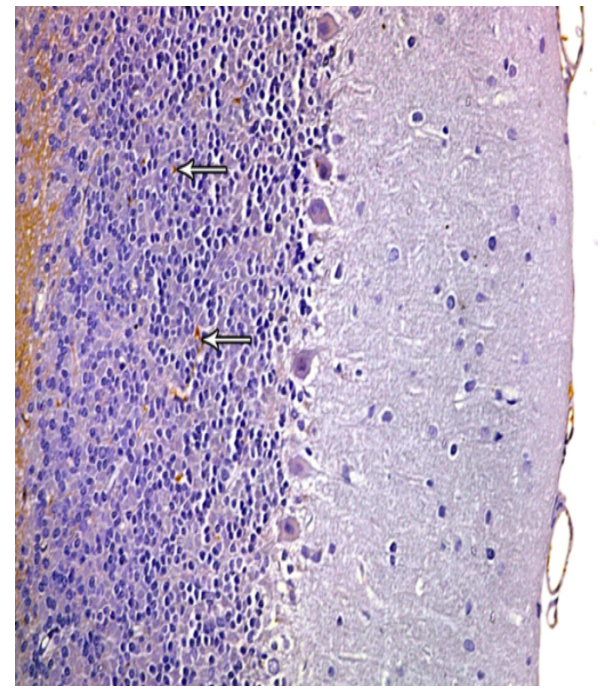

Fig 10: A photomicrograph of a section in cerebellar cortex of melatonin treated rat, three days after I/R, demonstrating few p53 -positive cells in the granular layer (arrows). (Anti p53 immunostaining $\mathrm{x} 400$ )

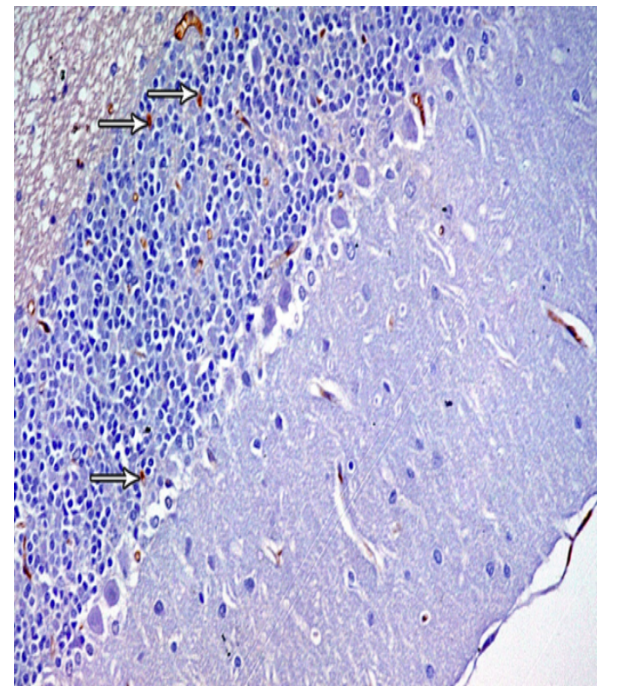

Fig 11: A photomicrograph of a section in cerebellar cortex of melatonin treated rat, one month after $\mathrm{I} / \mathrm{R}$, demonstrating apparent decrease in p53 positive cells (arrows). (Anti p53 immunostaining $\mathrm{x} 400$ )

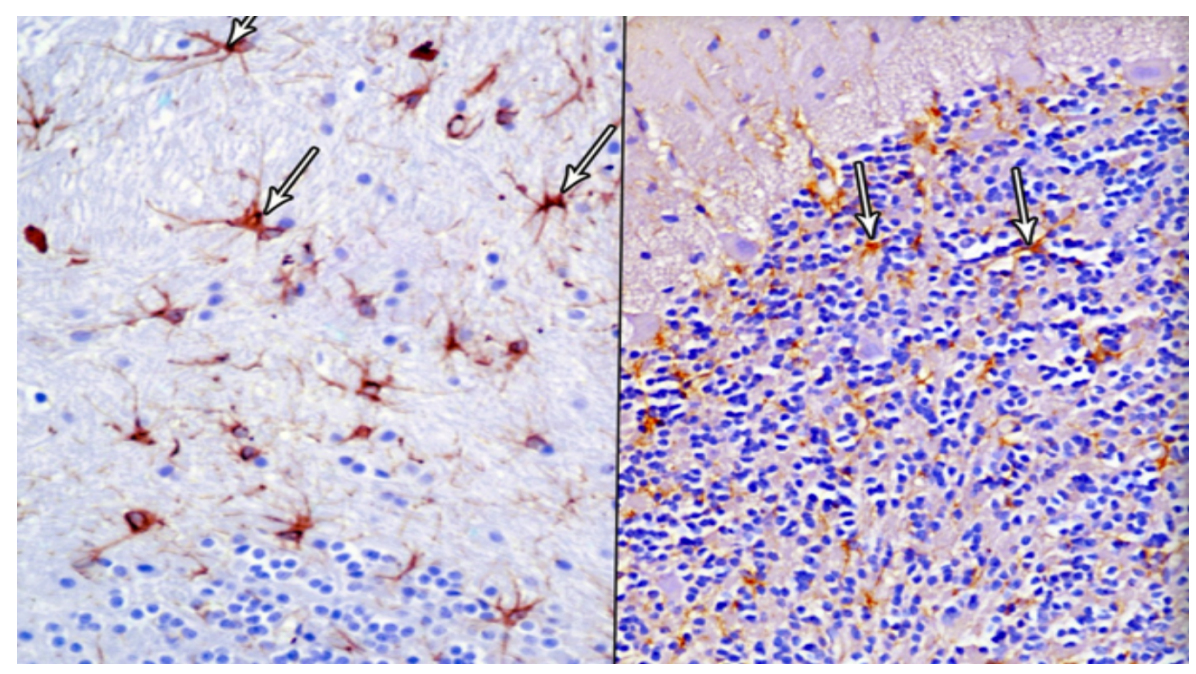

Fig 12: A Photomicrograph of positive control section in a rat cerebellar white matter (left side) showing cells (arrows) with strong positive reaction for GFAP and control rat cerebellar cortex (right side) with few GFAP positive ones (arrows). (Anti GFAP immunostaining $\mathrm{x}$ 400)

Vol. 43, No. 1 \& 2 Jan. \& April, 2014 


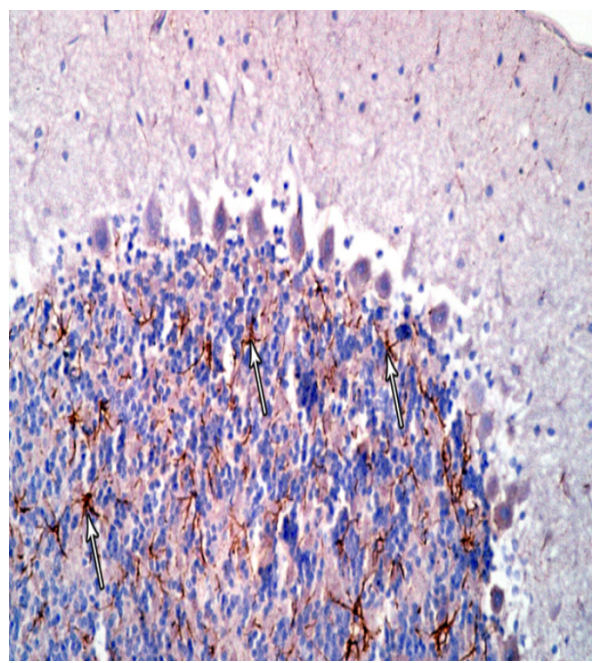

Fig 13: A photomicrograph of a section in a rat cerebellar cortex, three days after I/R, demonstrating an increase in GFAP -positive cells (arrows). (Anti GFAP immunostaining $\mathrm{x}$ 400)

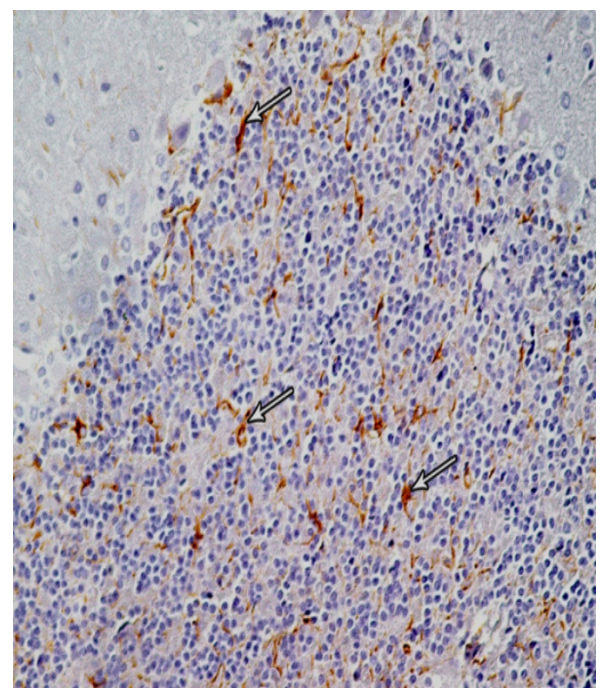

Fig 15: A photomicrograph of a section in cerebellar cortex of melatonin treated rat, three days after I/R, demonstrating few GFAP -positive astrocytes (arrows). (Anti GFAP immunostaining $\times 400$ )

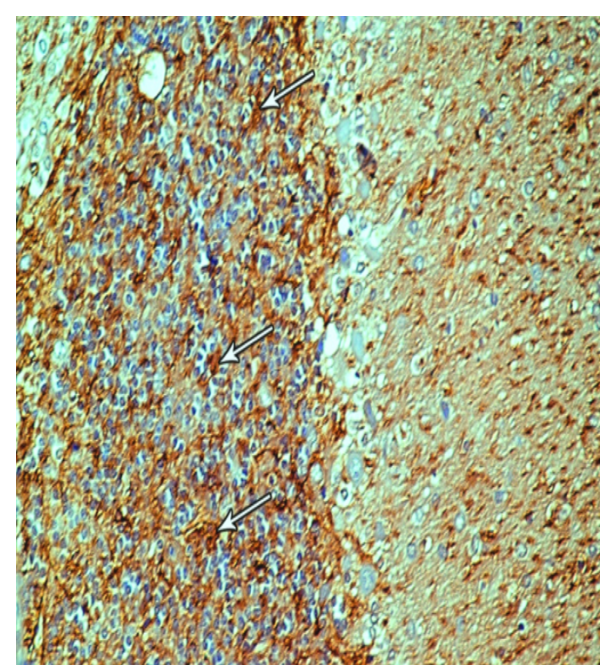

Fig 14: A photomicrograph of a section in a rat cerebellar cortex, one month after $I / R$, demonstrating an apparent marked increase in the number of GFAP -positive cells (arrows). (Anti GFAP immunostaining $\mathrm{x} 400$ )

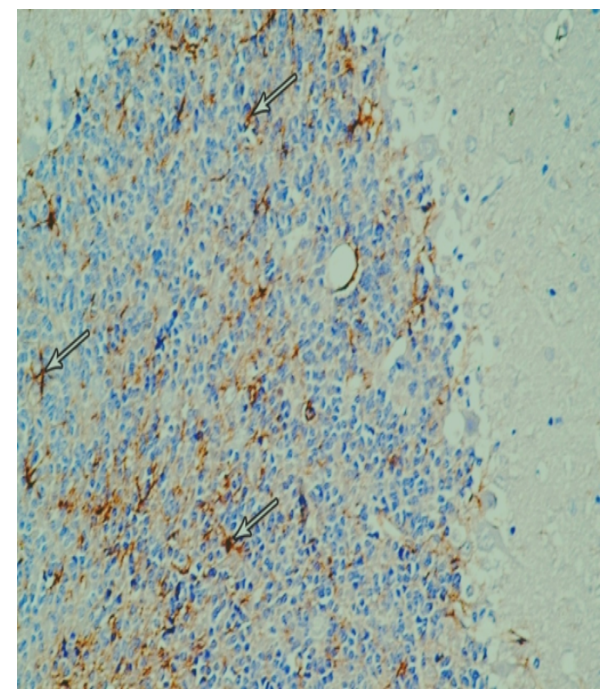

Fig 16: A photomicrograph of a section in cerebellar cortex of melatonin treated rat, one month after $I / R$, demonstrating an apparent decrease in GFAP -positive astrocytes (arrows). (Anti GFAP immunostaining $x$ 400)

MANSOURA MEDICAL JOURNAL 


\section{DISCUSSION}

The adult brain is extremely vulnerable to various insults. Ischemia is considered the most serious one that may result in both short and long term neurodegenerative and functional disorders $(48,49)$. The experimental studies concerning these issues are mostly confined to the first hours or days following the initiation of ischemia and observations on long-term or permanent ischemiainduced modifications are relatively rare (50).

Despite the dependence of cerebellar cortex in its blood supply mainly on vertebro-basilar system, deformed and necrotic Purkinje cells and many apoptotic granular cells with small eccentric nuclei were observed in the present study. These changes could be attributed to the connection networks between the damaged forebrain and cerebellum. In non-human primates and humans, the cortical areas of the forebrain make several axonal connections with the cerebellum via the pallidum, the thalamus and the pons (51). Moreover, it was mentioned that unilateral injury confined to the preterm cerebral hemisphere was associated with a significantly decreased vol- ume of the contralateral cerebellar hemisphere (52). In addition, indirect cerebellar injury may result from traumatic brain injury resulting in selective cerebellar Purkinje neuron loss (53). The indirect damage can be transmitted by several methods, such as mechanical forces, metabolic changes and presynaptic hyperexcitability (54).

Possible mechanical or functional injury of corticopontocerebellar pathway could affect the activity in the ipsilateral pons, and also the contralateral cerebellar cortex, a phenomenon known as crossed cerebellar diaschisis (55). Diaschisis was commonly observed in acute brain disorders, such as ischemic stroke, causing clinical deficits that exceed the functional consequences expected from the focal lesion with regard to its size and location in the brain. The experimental and clinical studies revealed decreased blood flow and metabolism in anatomically intact brain regions distant from a cerebral lesion, e.g., the cerebellar hemisphere contralateral to a lesion of the cerebral cortex. Reduced neuronal activity in the cerebral cortex led to a decrease in Purkinje cell activity in the contralateral cerebellar

Vol. 43, No. 1 \& 2 Jan. \& April, 2014 
Dalia A. Shabaan et al...

hemisphere, resulting from reduced of bilateral common carotid artery efferent excitatory activity in crossed occlusion (BCCAO) for 10 minutes projections (56). In a model of $\mathrm{I} / \mathrm{R}$, followed by reperfusion was used to crossed cerebellar diaschisis was examine the effect of the antioxidant shown to be a result of functional de- melatonin on indirect cerebellar injuactivation as well as transneuronal ry due to transient global cerebral isdegeneration (57). Six hours after chemia. Some researchers suggestmiddle cerebral artery occlusion in a ed that this model required a more mouse model of I/R, increased im- simple surgical preparation, that remunoreactivity for biliverdin reduc- perfusion could be readily accomtase, a sign of neuron damage, was found not only in the supratentorial ischemic core, but also in the Purkinje layer of the cerebellum (58).

Neuronal factors seem to be involved in impaired autoregulation not only in the cerebrum but also in the cerebellum in experimentally induced ischemia in the cerebrum. Sympathetic nerves are known to constrict cerebral blood vessels in response to changes in perfusion pressure. Cerebral ischemia activates the noradrenergic system of the brain, with large amounts of catecholamines being released in the ischemic site as well as from non ischemic nerve terminals, which in turn affect vasoreactivity to various stimuli such as autoregulation and CO2 response (59).

In the current study, a rat model plished, and that this model was easily suitable for chronic survival studies $(60,61)$.

The results of this study revealed the presence of many apoptotic granular cells and shrunken necrotic Purkinje ones in the cerebellar cortex three days after I/R injury. Some authors reported that apoptotic cell death may occured in addition to necrosis and apoptotic neurons could survive for some time but will continue to die for many hours or even days after ischemia $(9,62)$. Some authors assumed that the strongest pathophysiological activity could be observed 28 days after middle cerebral artery occlusion in a model of focal cerebral ischemia. They added that, an imbalance in cortical function persisted in the borderzone of the infarct up to six months after injury. These persistent changes in cel-

MANSOURA MEDICAL JOURNAL 


\section{HISTOLOGICAL AND IMMUNOHISTOCHEMICAL etc...}

lular function might be best explained by a permanent reorganization of the neocortical network, such as a loss of inhibitory control mechanisms and/or an augmentation of excitatory action (50).

Some authors described apoptosis as a program preferentially triggered by a microcirculatory disturbance $(63,64)$. Accordingly, apoptosis would significantly contribute to the neuronal damage in transient ischemia (65). Apoptotic cell death revealed characteristic morphological changes in H\&E staining, such as acidophilic change of cytoplasm and pyknosis of cell nuclei (66), whereas neuronal necrosis after global cerebral ischemia had been developed between the second and fourth days (67) and was manifested by karyolysis and cell organelles swelling (20).

The changes in the cerebellum after BCCAO are supported by some authors who demonstrated that chronic BCCAO in adult wistar rats leads to reduction of blood flow to the cerebellum and dilation of the basilar artery which ensures blood flow to the forebrain, changes in cortical astrocytes and decrease the number of Purkinje cells. This could be attributed to the remodeling of the basilar artery resulting in secondary vascular perturbations and an enlargement of its lumen over the course of days to weeks in young rats to become partially responsible for providing blood flow to the forebrain as a compensation for BCCAO (68).

In humans, many factors might play a role in delayed cell death observed after ischemic stroke including the neuronal excitability (69), released inflammatory mediators from reactive astrocytes (70) and reactive oxygen species which might be involved in creating the detrimental environment (71). In addition, post ischemic modifications in neuronal gene expression were thought to play a crucial role with regard to cell recovery or cell death. Different induction patterns of members of $c$-jun and c-fos genes, after global ischemia, are involved in postischemic selective vulnerability and apoptosis especially in the neocortex, pyramidal neurons of hippocampus and Purkinje cells of the cerebellum $(72,73)$.

Apoptosis was reported in many studies in ischemia $(74,75)$. p53 pro- 
tein plays a role in several modes of cell death depending in part upon its subcellular distributions $(76,77)$. It was suggested that apoptotic cells increased as early as 0.5 hour, peaked at 24 to 48 hours and persisted for 4 weeks after the onset of reperfusion and the process of apoptosis could be triggered at any time either during or after the insult (78). Similar results were also obtained by who declared that positive apoptotic cells were observed at 2 weeks and 1 month after injury (79).

In this study, rat cerebellar cortex showed relative increase in GFAPpositive astrocytes which was observed after three days and increased up to one month. These results are in agreement with some investigators $(80,81)$. Some of them reported that in experimental $\mathrm{I} / \mathrm{R}$, gliosis began at 72 hours post-stroke or later (80), while others mentioned that astroglial response in the core of the lesion started at 4 hours after the trauma and activation was observed up to 28 days after stroke onset (81).

Reactive changes in intermediate filaments in astrocytes, especially GFAP, had been shown to occur after various stimuli, including global ischemia (82). An early increase in GFAP immunoreactivity corresponded to the development of neuronal tolerance to subsequent ischemia after sublethal brief global ischemia (83). GFAP-upregulated astrocytes are able to uptake harmful substances, such as extracellular ions or excitatory neurotransmitters and to produce neurotrophic factors under pathological conditions (84).

Ischemic brain neuroprotection might be defined as any strategy, or combination of strategies, that antagonizes, interrupts or slows down the sequence of injurious biochemical and molecular events that eventually resulted in irreversible ischemic injury (85). Acceptance of the ROS and inflammatory theory has contributed to an increasing interest in the use of free radical scavengers and antiinflammatory agents as potential neuroprotective agents (9). In addition, long-term preservation of the neuronal population in cerebral vulnerable structures and their functions after acute global cerebral ischemia is a major end-point of neuroprotective strategies (86). Several studies have shown the neuroprotective effects of melatonin in adult models of $\mathrm{I} / \mathrm{R}$ both when the 
drug was administered before or after ischemia $(87,88)$.

In the present study, the histological architecture of cerebellar cortex appeared more or less similar to control group with few sporadic shrunken cells after injection of melatonin intraperitoneally, before and after I/R. These effects were maintained from three days up to one month. Another important finding of this study was the long lasting neuroprotective effect of melatonin. In addition, the number of p53 and GFAP positive cells showed statistically significant decrease, especially for GFAP positive cells, in melatonintreated subgroups as compared to the corresponding I/R subgroups in the cerebellar cortex.

It was found that pinealectomy led to greater infarcts in global ischemia (89). Furthermore, in experimental stroke in rats receiving rat-derived pineal gland allografts displayed reduced cerebral infarction than stroke rats that did not receive the transplants (90). In a model of global ischemia, a single post-ischemic melatonin infusion led to improvements in behavior and infarction volumes at 120 days $(91)$. However, these re- sults were disputed by investigators who used different models of global ischemia, where no significant differences in outcomes at 140 days after melatonin treatment (92).

The findings of this study were supported by some authors who described the long-lasting antiinflammatory effects of a single intraperitoneal injection of melatonin following 1 hour of middle cerebral artery occlusion (MCAO) plus 2-3 days of reperfusion (93). Also, it was reported that melatonin treatment (continuous i.v. infusion of $10 \mathrm{mg} / \mathrm{kg} / \mathrm{h}$ ) during the immediate six hours following a 15min global cerebral ischemia episode, resulted in a significant long term preservation of pyramidal neurons in the hippocampus as compared to neuron population of control animals when measured 90 days after the induction of global ischemia in rats (91). In addition, it was found that exogenous melatonin administration prevented the increases in cerebral and cerebellar cortical NO production after I/R injury in transient BCCAO in adult Mongolian gerbils (94).

The binding of melatonin to its receptors improved membrane fluidity 
and reduced $\mathrm{PMN}$ cell infiltration into damaged tissue via limiting the adhesion of leukocytes to endothelial cells, thus increasing blood flow and reducing edema (95). Decreased formation of oxidatively modified proteins and the upregulation of oxidative stress-responsive genes, such as Hsp70, used as indicator of astroglial stress, were consistent with a protective effect of melatonin (36). Melatonin could exert a wide range of antiapoptotic effects, mainly targeting mitochondria, thus enhancing cell survival pathways leading to cell rescue (95). It might be possible to treat neurodegenerative disorders by inhibiting mitochondrial cell death pathways and promoting mitochondrial homeostasis (96).

Melatonin had been demonstrated to reduce the expression of GFAP, whose accumulation was related to the creation of new astrocytic processes and reactive gliosis (97, 98). In contrast, it was found that melatonin treatment did not influence I/R-induced GFAP response and might not mediate neuroprotective actions following $\mathrm{I} / \mathrm{R}$ via astrocytic mechanisms (37). Moreover, several studies suggested that melatonin may be of therapeutic value in ameli- orating hypoxic-ischemic $(\mathrm{H} / \mathrm{l})$ damage of myelinated nerve fibers through normalization of the myelination process $(98,99)$.

The improvement observed with melatonin administration a neuroprotective drug are related to its bioavailability, its potential for exerting wide-spread neuroprotective actions, further amplified and prolonged by its metabolites (100), its ability to reduce inflammation, its capability to protect cytoskeleton organization, and its anti-apoptotic actions. Moreover, melatonin does not interfere with the thrombolytic and neuroprotective actions of other drugs (36). Infarct volume, amount of edema, frequency of apoptosis, degree of glial activation, quantity of oxidized macromolecules, degree of neurological deficits, molecular alterations have all been shown to be improved if the animals are given melatonin at the time or shortly after induction of transient ischemia and subsequent reperfusion (101). Melatonin also promotes neurogenesis by suppressing inflammation and more extensive studies are required to examine these points. Overall, melatonin treatment showed long term benefits in experimental I/R studies as a re-

MANSOURA MEDICAL JOURNAL 
sult of better preserved brain tissues in the acute stage (102).

\section{Conclusion}

On the basis of the current study, it can be concluded that melatonin administration in $\mathrm{I} / \mathrm{R}$ could ameliorate the associated histological and immunohistochemical changes in rat cerebellar cortex with long term benefits.

\section{REFERENCES}

1. Jacobson, S. and Marcus, E.M. (2008) : Neuroanatomy for the Neuroscientist. Springer, 273-80.

2. Reiter, R.; Tan, D.; FuentesBroto, L.; Paredes, S. D.; Rcelo, E. S.-B. and Mediavilla, M. D. (2010) : Melatonin salvages neural tissue from ischemia/reperfusion injury. The Open Neuroendocrinology Journal, 3:11220.

3. Patestas, M. and Gartner, L. P. (2006) : A Textbook of Neuroanatomy. Blackwell, 220-36.

4. Tatlisumak, E.; Inan, S.; Asirdizer, M.; Apaydin, N.;
Hayretdag, C.; Kose, C. and Tekdemir, I. (2009) : Defining the Macroscopic and Microscopic Findings of Experimental Focal Brain Ischemia in Rats from a Forensic Scientist's Point of View. The American journal of forensic medicine and pathology, 30(1): 26-31.

5. Barber, P. A.; Hoyte, L.; Colbourne, F. and Buchan, A. M. (2004) : Temperature-regulated model of focal ischemia in the mouse: a study with histopathological and behavioral outcomes. Stroke, 35(7): 1720-5.

6. Kollmar, R.; Blank, T.; Han, J. L.; Georgiadis, D. and Schwab, S. (2007) : Different degrees of hypothermia after experimental stroke: short- and long-term outcome. Stroke, 38(5): 15859.

7. Cole, G. and Cowie, V. (1987) : Long survival after cardiac arrest: case report and 
neuropathological findings.

Clinical neuropathology, 6

(3): 104-09.

8. Eltzschig, H. K. and Collard, C.

D. (2004) : Vascular ischaemia and reperfusion injury. Br Med Bull, 70:7186.

9. Wang, X.; Hagberg, H.; Zhu, C.; Jacobsson, B. and Mallard, C. (2007) : Effects of intrauterine inflammation on the developing mouse brain. Brain research, 1144:180-85.

10. Ribo, M.; Rubiera, M.; Pagola, J.; Rodriguez-Luna, D.; Meler, P.; Flores, A.; Alvarez-Sabin, J. and Molina, C. (2010) : Bringing forward reperfusion with oxygenated blood perfusion beyond arterial occlusion during endovascular procedures in patients with acute ischemic stroke. American Journal of Neuroradiology, 31(10): 1899902.

11. Flores, A.; Sargento-Freitas,
J.; Pagola, J.; RodriguezLuna, D.; Piñeiro, S.; Maisterra, O.; Rubiera, M.; Montaner, J.; AlvarezSabin, J. and Molina, C. (2013) : Arterial blood gas analysis of samples directly obtained beyond cerebral arterial occlusion during endovascular procedures predicts clinical outcome. Journal of Neuroimaging, 23(2): 180-84.

12. Montaner, J.; Mendioroz, M.; Ribó, M.; Delgado, P.; Quintana, M.; Penalba, A.; Chacón, P.; Molina, C.; Fernández-Cadenas, I. and Rosell, A. (2011) : A panel of biomarkers including caspase-3 and D-dimer may differentiate acute stroke from strokemimicking conditions in the emergency department. Journal of internal medicine, 270(2): 166-74.

13. Navarro-Sobrino, M.; Rosell, A.; Hernandez-Guillamon, M.; Penalba, A.; Ribó, M.; Alvarez-Sabín, J. and Montaner, J. (2010) : MoMANSOURA MEDICAL JOURNAL 
bilization, endothelial differentiation and functional capacity of endothelial progenitor cells after ischemic stroke. Microvascular research, 80(3): 317-23.

14. Massot, A.; Navarro-Sobrino, M.; Penalba, A.; Arenillas, J.; Giralt, D.; Ribó, M.; Molina, C.; Alvarez-Sabín, J.; Montaner, J. and Rosell, A. (2013) : Decreased levels of angiogenic growth factors in intracranial atherosclerotic disease despite severity-related increase in endothelial progenitor cell counts. Cerebrovascular diseases (Basel, Switzerland), 35(1): 81-88.

15. Ross, A. M.; Hurn, P.; Perrin, N.; Wood, L.; Carlini, W. and Potempa, K. (2007) : Evidence of the peripheral inflammatory response in patients with transient ischemic attack. J Stroke Cerebrovasc Dis, 16(5): 2037.

16. Iadecola, C. and Alexander, M. (2001) : Cerebral ische-

Vol. 43, No. 1 \& 2 Jan. \& April, 2014 mia and inflammation. Current opinion in neurology, 14(1): 89-94.

17. Clarkson, A. N.; Sutherland, B. A. and Appleton, I. (2005) : The biology and pathology of hypoxiaischemia: an update. Archivum Immunologiae et Therapiae ExperimentalisEnglish Edition, 53(3): 213.

18. Wei, L.; Ying, D.-J.; Cui, L.; Langsdorf, J. and Yu, S. P. (2004) : Necrosis, apoptosis and hybrid death in the cortex and thalamus after barrel cortex ischemia in rats. Brain research, 1022(1): 54-61.

19. Lipton, P. (1999) : Ischemic cell death in brain neurons. Physiological reviews, 79 (4): 1431-568.

20. Studzinski, G. P. (1999) : Apoptosis: a practical approach. Oxford University Press New York, NY, USA, 31-3.

21. Chamoun, F.; Burne, M.; 
O'Donnell, M. and Rabb, H. (2000) : Pathophysiologic role of selectins and their ligands in ischemia reperfusion injury. Front Biosci, 1 (5): 103-9.

22. Gupta, S.; Gupta, Y. K. and Sharma, S. S. (2007) : Protective effect of pifithrinalpha on brain ischemic reperfusion injury induced by bilateral common carotid arteries occlusion in gerbils. Indian J Physiol Pharmacol, 51(1): 62-8.

23. Green, D. R. and Kroemer, G. (2009) : Cytoplasmic functions of the tumour suppressor p53. Nature, 458 (7242): 1127-30.

24. Meulmeester, E. and Jochemsen, A. G. (2008) : p53: a guide to apoptosis. Current cancer drug targets, 8(2): 87-97.

25. Back, T. and Schuler, O. G. (2004) : The natural course of lesion development in brain ischemia. Acta Neurochir Suppl, 89:55-61.
26. Fitch, M. T. and Silver, J. (2008) : CNS injury, glial scars, and inflammation: Inhibitory extracellular matrices and regeneration failure. Exp Neurol, 209(2): 294-301.

27. Pekny, M. and Nilsson, $M$. (2005) : Astrocyte activation and reactive gliosis. Glia, 50(4): 427-34.

28. Sofroniew, M. V. and Vinters, H. V. (2010) : Astrocytes: biology and pathology. Acta Neuropathol, 119(1): 7-35.

29. Nolte, C.; Matyash, M.; Pivneva, T.; Schipke, C. G.; Ohlemeyer, C.; Hanisch, U. K.; Kirchhoff, F. and Kettenmann, H. (2001) : GFAP promoter-controlled EGFP-expressing transgenic mice: A tool to visualize astrocytes and astrogliosis in living brain tissue. Glia, 33(1): 72-86.

30. Maresova, D.; Riljak, V. and Mares, J. (2010) : Melatonin modulates hypoxiaMANSOURA MEDICAL JOURNAL 
induced changes of rat brain excitability. Gen Physiol Biophys, 29(1): 6771.

31. Paredes, S. D.; Korkmaz, A.; Manchester, L. C.; Tan, D. X. and Reiter, R. J. (2009) : Phytomelatonin: a review. J Exp Bot, 60(1): 57-69.

32. Costa, E. J.; Lopes, R. H. and Lamy-Freund, M. T. (1995) : Permeability of pure lipid bilayers to melatonin. J Pineal Res, 19(3): 123-6.

33. Reiter, R. J. (1998) : Oxidative damage in the central nervous system: protection by melatonin. Prog Neurobiol, 56(3): 359-84.

34. Cheung, R. T.; Tipoe, G. L.; Tam, S.; Ma, E. S.; Zou, L. Y. and Chan, P. S. (2006)

: Preclinical evaluation of pharmacokinetics and safety of melatonin in propylene glycol for intravenous administration. J Pineal Res, 41(4): 337-43.

Vol. 43, No. 1 \& 2 Jan. \& April, 2014
35. Macchi, M. M. and Bruce, J. N. (2004) : Human pineal physiology and functional significance of melatonin. Front Neuroendocrinol, 25 (3-4): 177-95.

36. Esposito, E. and Cuzzocrea, S. (2010) : Antiinflammatory activity of melatonin in central nervous system. Current neuropharmacology, 8(3): 228.

37. Pei, Z. and Cheung, R. T. F. (2003) : Melatonin protects SHSY5Y neuronal cells but not cultured astrocytes from ischemia due to oxygen and glucose deprivation. Journal of pineal research, 34(3): 194-201.

38. Cheung, R. T. F. (2003) : The utility of melatonin in reducing cerebral damage resulting from ischemia and reperfusion. Journal of pineal research, 34(3): 153-60.

39. Husson, I.; Mesples, B.; Bac, P.; Vamecq, J.; Evrard, P. and Gressens, P. (2002) : Melatoninergic neuropro- 
tection of the murine periventricular white matter against neonatal excitotoxic challenge. Annals of neurology, 51(1): 82-92.

40. Jiao, S.; Wu, M. M.; Hu, C. L.; Zhang, Z. H. and Mei, Y. A. (2004) : Melatonin receptor agonist 2iodomelatonin prevents apoptosis of cerebellar granule neurons via $\mathrm{K}+$ current inhibition. Journal of pineal research, 36(2): 109-16.

41. Schwartz-Bloom, R.; Miller, K.; Evenson, D.; Crain, B. and Nadler, J. (2000) : Benzodiazepines protect hippocampal neurons from degeneration after transient cerebral ischemia: an ultrastructural study. Neuroscience, 98(3): 471-84.

42. Moroni, F.; Meli, E.; Peruginelli, F.; Chiarugi, A.; Cozzi, A.; Picca, R.; Romagnoli, P.; Pellicciari, R. and Pellegrini-Giampietro, $D$. (2001) : Poly (ADP-ribose) polymerase inhibitors at- tenuate necrotic but not apoptotic neuronal death in experimental models of cerebral ischemia. Cell death and differentiation, 8(9): 921-32.

43. Ajao, M. S.; Olaleye, O. and Ihunwo, A. O. (2010) : Melatonin potentiates cells proliferation in the dentate gyrus following ischemic brain injury in adult rats. $J$ Anim Vet Adv, 9(11): 163338.

44. Iwai, M.; Sato, K.; Kamada, H.; Omori, N.; Nagano, I.; Shoji, M. and Abe, K. (2003) : Temporal profile of stem cell division, migration, and differentiation from subventricular zone to olfactory bulb after transient forebrain ischemia in gerbils. Journal of Cerebral Blood Flow \& Metabolism, 23(3): 331-41.

45. Petri, E. S.; Ajao, M. S.; Olaleye, 0 . and Ihunwo, A. 0. (2011) : Effect of melatonin on neuronal nitric oxide synthase expressing cells

MANSOURA MEDICAL JOURNAL 
in the brain following global cerebral ischemia. $J$ Anim Vet Adv, 10:395-400.

46. Bancroft, J.D. and Layton, C. (2013) : The hematoxylins and eosin. In: Bancroft's Theory and Practice of Histological Techniques. (eds. Suvarna, S.K., Layton, C. and Bancroft, J.D.). Seventh ed. Churchill Livingstone Elsevier. Oxford, 173-86.

47. Bancroft, D.J. and Gamble, M. (2002) : Immunocytochemistry in practice. In: Theory and Practice of Histological Techniques. Fifth ed. Churchill Livingstone London, New York, 438-44.

48. Nakatomi, H.; Kuriu, T.; Okabe, S.; Yamamoto, S.i.; Hatano, O.; Kawahara, N.; Tamura, A.; KI/Rno, T. and Nakafuku, M. (2002) : Regeneration of hippocampal pyramidal neurons after ischemic brain injury by recruitment of endogenous neural progenitors. Cell,
110(4): 429-41.

49. Tarozzi, A.; Angeloni, C.; Malaguti, M.; Morroni, F.; Hrelia, S. and Hrelia, P. (2013) : Sulforaphane as a potential protective phytochemical against neurodegenerative diseases. Oxidative medicine and cellular longevity, 1-10.

50. Mittmann, T.; Qü, M.; Zilles, $K$. and Luhmann, $H$. (1998) : Long-term cellular dysfunction after focal cerebral ischemia: in vitro analyses. Neuroscience, 85(1): 15-27.

51. Biran, V.; Heine, V. M.; Verney, C.; Sheldon, R. A.; Spadafora, R.; Vexler, Z. S.; Rowitch, D. H. and Ferriero, D. M. (2011) : Cerebellar abnormalities following hypoxia alone compared to hypoxic-ischemic forebrain injury in the developing rat brain. Neurobiology of disease, 41(1): 138-46.

52. Limperopoulos, C.; Soul, J. 
S.; Haidar, H.; Huppi, P. S.; Bassan, H.; Warfield, S. K.; Robertson, R. L.; Moore, M.; Akins, P. and Volpe, J. J. (2005) : Impaired trophic interactions between the cerebellum and the cerebrum among preterm infants. Pediatrics, 116(4): 844-50.

53. Park, E.; McKnight, S.; Ai, J. and Baker, A. J. (2006) : Purkinje cell vulnerability to mild and severe forebrain head trauma. Journal of Neuropathology \& Experimental Neurology, 65(3): 226-34.

54. Potts, M. B.; Adwanikar, $H$. and Noble-Haeusslein, L. J. (2009) : Models of traumatic cerebellar injury. The Cerebellum, 8(3): 21121.

55. Infeld, B.; Davis, S. M.; Lichtenstein, M.; Mitchell, P. J. and Hopper, J. L. (1995) : Crossed cerebellar diaschisis and brain recovery after stroke. Stroke, 26 (1): 90-95.
56. Gold, L. and Lauritzen, $M$. (2002) : Neuronal deactivation explains decreased cerebellar blood flow in response to focal cerebral ischemia or suppressed neocortical function. Proceedings of the National Academy of Sciences, 99(11): 7699-704.

57. Liu, Y.; Karonen, J. O.; Nuutinen, J.; Vanninen, E.; Kuikka, J. T. and Vanninen, R. L. (2007) : Crossed cerebellar diaschisis in acute ischemic stroke: a study with serial SPECT and MRI. Journal of Cerebral Blood Flow \& Metabolism, 27(10): 1724-32.

58. Panahian, N.; Huang, T. and Maines, M. D. (1999) : Enhanced neuronal expression of the oxidoreductase-biliverdin reductase-after permanent focal cerebral ischemia. Brain research, 850(1): 113.

59. Shiokawa, O.; Sadoshima, S.; Fujii, K.; Yao, H. and FuMANSOURA MEDICAL JOURNAL 
66

jishima, M. (1988) : Impairment of cerebellar blood flow autoregulation during cerebral ischemia in spontaneously hypertensive rats. Stroke, 19(5): 615-22.

60. Traystman, R. J. (2003) : Animal models of focal and global cerebral ischemia. ILAR journal, 44(2): 85-95.

61. Vekaria, R. H.; Patel, M. N.; Bhalodiya, P. N.; Patel, V.; Desai, T. R. and Tirgar, P. R. (2012) : Evaluation of neuroprotective effect of Coriandrum sativum linn. against ischemicreperfusion insult in brain. Internatational Journal of Phytopharmacology, 3(2): 186-93.

62. Fisher, M. (1997) : Characterizing the target of acute stroke therapy. Stroke, 28 (4): 866-72.

63. Chopp, M. and Li, Y. (1996) : Apoptosis in focal cerebral ischemia. Springer. 66: 21-6.

Vol. 43, No. 1 \& 2 Jan. \& April, 2014
64. Vexler, Z. S.; Roberts, T.; Bollen, A. W.; Derugin, N. and Arieff, A. I. (1997) : Transient cerebral ischemia. Association of apoptosis induction with hypoperfusion. Journal of Clinical Investigation, 99(6): 1453.

65. Andersson, B.; Bjelke, B. and Sykova, E. (2006) : Temporal profile of ultrastructural changes in cortical neurones after a compression lesion. Physiol Res, 55(3): 339-48.

66. Hockenbery, D. (1995) : Defining apoptosis. The American journal of pathology, 146(1): 16 .

67. Oehmichen, M.; Auer, R. N. and König, H. G. (2006) : Forensic neuropathology and associated neurology. Springer-Verlag, Berlin, Germany, 273-88.

68. Kántor, O.; Schmitz, C.; Feiser, J.; Brasnjevic, I.; Korr, H.; Busto, R.; Ginsberg, M. D. and SchmidtKastner, R. (2007) : Mod- 
erate loss of cerebellar Purkinje cells after chronic bilateral common carotid artery occlusion in rats. Acta neuropathologica, 113(5): 549-58.

69. Ayata, C. and Ropper, A. H. (2002) : Ischaemic brain oedema. Journal of Clinical Neuroscience, 9(2): 11324.

70. Brambilla, R.; BracchiRicard, V.; Hu, W.-H.; Frydel, B.; Bramwell, A.; Karmally, S.; Green, E. J. and Bethea, J. R. (2005) : Inhibition of astroglial nuclear factor $\kappa B$ reduces inflammation and improves functional recovery after spinal cord injury. The Journal of experimental medicine, 202(1): 145-56.

71. Swanson, R. A.; Ying, W. and Kauppinen, T. M. (2004) : Astrocyte influences on ischemic neuronal death. Current molecular medicine, 4(2): 193-205.

72. Akins, P. T.; Liu, P. K. and
Hsu, C. Y. (1996) : Immediate early gene expression in response to cerebral ischemia friend or Foe? Stroke, 27(9): 1682-87.

73. Honkaniemi, J.; Massa, S. M.; Breckinridge, $M$. and Sharp, F. R. (1996) : Global ischemia induces apoptosis-associated genes in hippocampus. Molecular brain research, 42(1): 7988.

74. Zgavc, T.; Ceulemans, A.-G.; Hachimi-Idrissi, S.; Kooijman, R.; Sarre, S. and Michotte, Y. (2012) : The neuroprotective effect of post ischemic brief mild hypothermic treatment correlates with apoptosis, but not with gliosis in endothelin-1 treated rats. BMC neuroscience, 13(1): 105.

75. Pei, L.; Shang, Y.; Jin, H.; Wang, S.; Wei, N.; Yan, H.; Wu, Y.; Yao, C.; Wang, $X$. and Zhu, L.-Q. (2014) : DAPK1-p53 Interaction Converges Necrotic and Apoptotic Pathways of

MANSOURA MEDICAL JOURNAL 
Ischemic Neuronal Death.

The Journal of neuroscience, 34(19): 6546-56.

76. Brady, C. A.; Jiang, D.; Mello, S. S.; Johnson, T. M.; Jarvis, L. A.; Kozak, M. M.; Broz, D. K.; Basak, S.; Park, E. J. and McLaughlin, M. E. (2011) : Distinct p53 transcriptional programs dictate acute DNAdamage responses and tumor suppression. Cell, 145 (4): 571-83.

77. Vaseva, A. V.; Marchenko, N. D.; Ji, K.; Tsirka, S. E.; Holzmann, S. and Moll, U. M. (2012) : p53 opens the mitochondrial permeability transition pore to trigger necrosis. Cell, 149(7): 1536-48.

78. Li, Y.; Chopp, M.; Jiang, N.; Yao, F. and Zaloga, C. (1995) : Temporal profile of in situ DNA fragmentation after transient middle cerebral artery occlusion in the rat. Journal of Cerebral Blood Flow \& Metabolism, 15(3): 389-97.
79. Conti, A. C.; Raghupathi, R.; Trojanowski, J. Q. and McIntosh, T. K. (1998) : Experimental brain injury induces regionally distinct apoptosis during the acute and delayed post-traumatic period. The Journal of neuroscience, 18(15): 566372.

80. Du Bois, M.; Bowman, P. D. and Goldstein, G. W. (1985) : Cell proliferation after ischemic infarction in gerbil brain. Brain research, 347(2): 245-52.

81. Nowicka, D.; Rogozinska, K.; Aleksy, M.; Witte, O. W. and Skangiel-Kramska, J. (2008) : Spatiotemporal dynamics of astroglial and microglial responses after photothrombotic stroke in the rat brain. Acta neurobiologiae experimentalis, 68 (2): 155-68.

82. Ordy, J.; Wengenack, T.; Bialobok, P.; Coleman, P.; Rodier, P.; Baggs, R.; Dunlap, W. and Kates, B. (1993) : Selective vulnera- 
Dalia A. Shabaan et al...

bility and early progression of hippocampal CA1 pyramidal cell degeneration and GFAP-positive astrocyte reactivity in the rat four-vessel occlusion model of transient global ischemia. Experimental neurology, 119(1): 128-39.

83. Kato, H.; Kogure, K.; Araki, T. and Itoyama, Y. (1994) : Astroglial and microglial reactions in the gerbil hippocampus with induced ischemic tolerance. Brain research, 664(1): 69-76.

84. Matsushima, K.; SchmidtKastner, R.; Hogan, M. J. and Hakim, A. M. (1998) : Cortical spreading depression activates trophic factor expression in neurons and astrocytes and protects against subsequent focal brain ischemia. Brain research, 807(1): 47-60.

85. Ginsberg, M. D. (2009) : Current status of neuroprotection for cerebral ischemia synoptic overview. Stroke, 40: S111-S14.
86. García-Chávez, D.; GonzálezBurgos, I.; LetechipíaVallejo, G.; López-Loeza, E.; Moralí, G. and Cervantes, M. (2008) : Longterm evaluation of cytoarchitectonic characteristics of prefrontal cortex pyramidal neurons, following global cerebral ischemia and neuroprotective melatonin treatment, in rats. Neuroscience letters, 448(1): 148-52.

87. Sachdev, P.; Brodaty, H.; Valenzuela, M.; Lorentz, L.; Looi, J.; Berman, K.; Ross, A.; Wen, W. and Zagami, A. (2006) : Clinical determinants of dementia and mild cognitive impairment following ischaemic stroke: the Sydney Stroke Study. Dementia and geriatric cognitive disorders, 21 (5): 275-83.

88. Yukie, M.; Yamaguchi, K. and Yamashima, $T$. (2006) : Impairments in Recognition Memory for Object and for Location MANSOURA MEDICAL JOURNAL 
after Transcnt Brain Ischemia in Monkeys. Reviews in the neurosciences, 17(12): 201-14.

89. Manev, H.; Uz, T.; Kharlamov, A. and Joo, J. (1996) : Increased brain damage after stroke or excitotoxic seizures in melatonin-deficient rats. The FASEB journal, 10(13): 1546-51.

90. Borlongan, C.; Sumaya, I.; Moss, D.; Kumazaki, M.; Sakurai, T.; Hida, H. and Nishino, H. (2003) : Melatonin-secreting pineal gland: a novel tissue source for neural transplantation therapy in stroke. Cell transplantation, 12(3): 225-34.

91. Letechipía-Vallejo, G.; LópezLoeza, E.; EspinozaGonzález, V.; GonzálezBurgos, I.; Olvera-Cortés, M. E.; Moralí, G. and Cervantes, M. (2007) : Longterm morphological and functional evaluation of the neuroprotective effects of post-ischemic treatment with melatonin in rats. Journal of pineal research, 42 (2): 138-46.

92. Rennie, K.; De Butte, M.; Fréchette, M. and Pappas, B. A. (2008) : Chronic and acute melatonin effects in gerbil global forebrain ischemia: long-term neural and behavioral outcome. Journal of pineal research, 44(2): 149-56.

93. Pei, Z. and Cheung, R. T. F. (2004) : Pretreatment with melatonin exerts antiinflammatory effects against ischemia/ reperfusion injury in a rat middle cerebral artery occlusion stroke model. Journal of pineal research, 37 (2): 85-91.

94. Guerrero, J. M.; Reiter, R. J.; Ortiz, G. G.; Pablos, M. I.; Sewerynek, E. and Chuang, J. I. (1997) : Melatonin prevents increases in neural nitric oxide and cyclic GMP production after transient brain ischemia and reperfusion in the Mon- 
golian gerbil (Meriones unguiculatus). Journal of pineal research, 23(1): 2431.

95. Alonso-Alconada, D.;

Álvarez, A.; Arteaga, 0.; Martínez-lbargüen, $A$. and Hilario, E. (2013) : Neuroprotective effect of melatonin: a novel therapy against perinatal hypoxiaischemia. International journal of molecular sciences, 14(5): 9379-95.

96. Túnez, I.; Montilla, P.; Del Carmen Munoz, M.; Feijóo, M. and Salcedo, M. (2004) : Protective effect of melatonin on 3nitropropionic acid-induced oxidative stress in synaptosomes in an animal model of Huntington's disease. Journal of pineal research, 37(4): 252-56.

97. Hutton, L. C.; Abbass, M.; Dickinson, H.; Ireland, Z. and Walker, D. W. (2008) : Neuroprotective properties of melatonin in a model of birth asphyxia in the spiny mouse (Acomys cahirinus). Developmental neuroscience, 31(5): 437-51.

98. Alonso-Alconada, D.; Alvarez, A.; Lacalle, J. and Hilario, E. (2012) : Histological study of the protective effect of melatonin on neural cells after neonatal hypoxia-ischemia. Histology and histopathology, 27 (6): 771-83.

99. Villapol, S.; Fau, S.; Renolleau, S.; Biran, V.; Charriaut-Marlangue, C. and Baud, O. (2011) : Melatonin promotes myelination by decreasing white matter inflammation after neonatal stroke. Pediatric research, 69(1): 51-55.

100. Peyrot, F. and Ducrocq, C. (2008) : Potential role of tryptophan derivatives in stress responses characterized by the generation of reactive oxygen and nitrogen species. J Pineal Res, 45(3): 235-46.

101. Pandi-Perumal, S. R.; SrinivMANSOURA MEDICAL JOURNAL 
72 HISTOLOGICAL AND IMMUNOHISTOCHEMICAL etc...

asan, V.; Maestroni, G.J.; 102. Lin, H.-W. and Lee, E.J. Cardinali, D. P.; Poeggel- (2009) : Effects of melatoer, B. and Hardeland, R. nin in experimental stroke (2006) : Melatonin: Na- models in acute, sub-acute, ture's most versatile bio- and chronic stages. Neurological signal? Febs J, psychiatr Dis Treat, 5:157273(13): 2813-38.

62. 


\section{دراسة هستولوجية وهستوكيميائية مناعية لتأثير الميلاتونين على إصابة قشرة المخيخ فى الفأربعد ربط مؤقت للشريان السباتي المشترك فى الناحيتين}

يشير نقص تروية المخخ إلى عدم كفاية تدفق الدم لتلبية إحتياجاته من التمثيل الغذائى مما

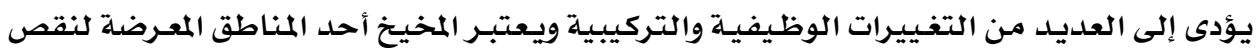

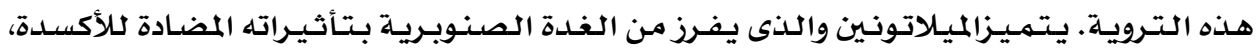

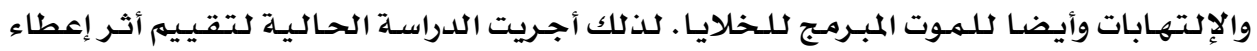

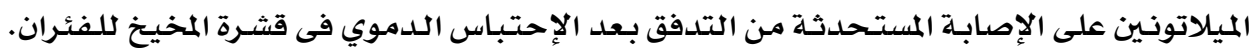

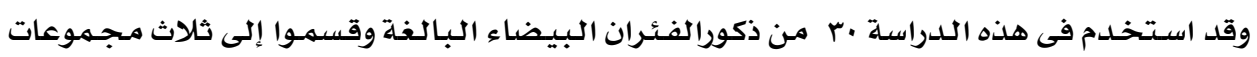

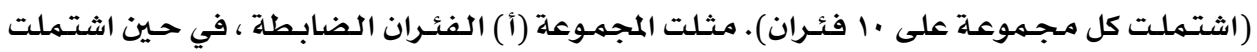

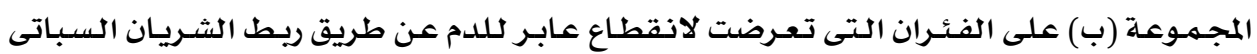

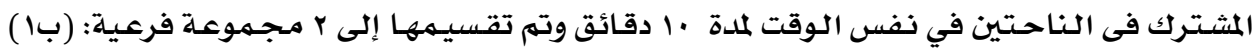

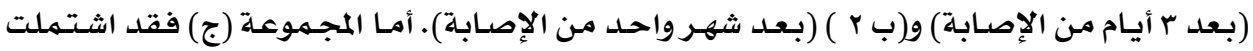

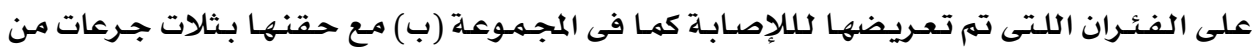

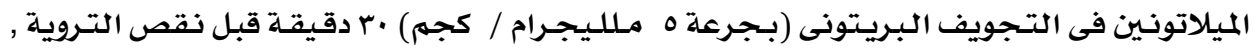

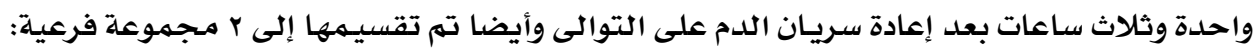

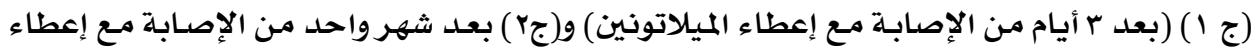

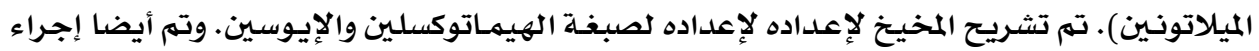

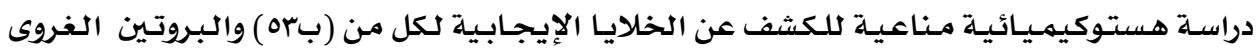

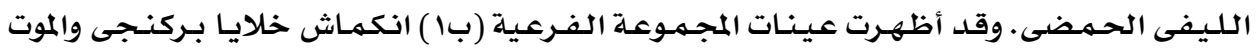

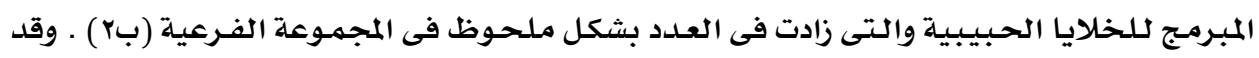

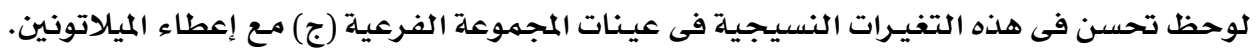

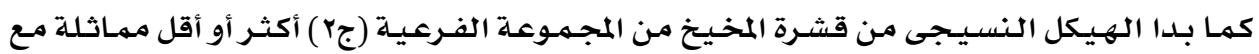

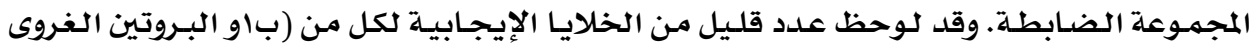

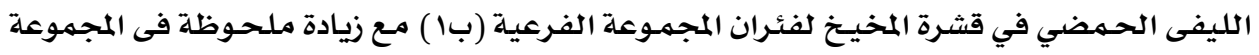

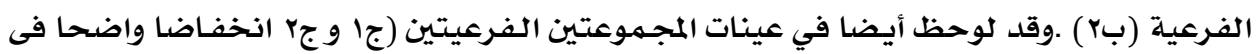

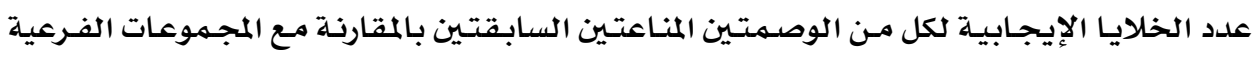

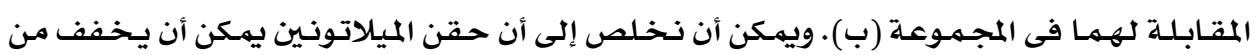

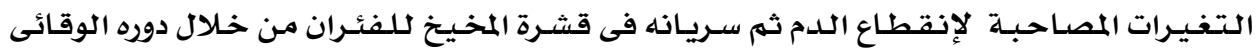

